$\$$ sciendo

\title{
Physicalism and Early Behaviourism
}

Nelson Gonçalves Gomes

University of Brasília

Disputatio Vol. 4, No. 34

December 2012

DOI: $10.2478 / \operatorname{disp}-2012-0025$

ISSN: 0873-626X 


\title{
Physicalism and Early Behaviourism
}

\author{
Nelson Gonçalves Gomes \\ University of Brasília \\ BIBL[0873-626X (2012) 34. pp. 635-643]
}

In the history of philosophy very few thinkers opposed metaphysics in such a radical way as Otto Neurath (1882-1945), a member of the so called First Vienna Circle (1907-12), and an active participant in the Moritz Schlick's privatissimum that regularly met for fifteen years from October 1923 onwards. Neurath was a fertile thinker, as he wrote over five hundred different works comprehending areas like philosophy, economics, sociology, and education. He was also a restless social organiser and editor of scientific publications. It is true that mostly of his essays are rather short and full of repetitions, but his thought was in continuous transformation from his very first work on (1909). In the present article we will concentrate on the ideas developed by Neurath on physicalism in the late 1920 and in the first half of the 1930s. In that period Schlick's privatissimum was termed Vienna Circle thank to the publication of the well known manifesto, which was actually written by Neurath with some opinion by other fellow-members especially Carnap. Philosophically the manifesto was a compromise between some intellectual tendencies within the Circle, which is a reason why it is not the best reference for someone who wants to understand Neurath's anti-philosophy. In these lines we will present the Neurathian view of physicalism. Our effort will be to show that early behaviourist psychology was introduced in it as a crucial element to complete what Neurath believed to be a radical version of materialism.

In a review of Carnap's Aufbau written in a political newspaper in 1928 Neurath speaks favourably about the anti-metaphysical tendency of the book but he clearly expresses his objections relative to the limits of some Carnapian claims to sharp logical order and theoreti-

Disputatio, Vol. IV, No. 34, December 2012 
cal exactness. (Neurath 1981/1928: 295-7) Accordingly to Neurath a sociologist knows that ambiguity is unavoidable to a certain extent, which gives rise to problems that only explicit ideological choices may solve. He was indeed a materialist deeply engaged in the project of a Marxian sort of society. Science for him is a revolutionary power, capable of forecasting what is going to happen. This wonderful ability of science makes it possible for mankind to find reliable guidance about individual and especially about collective decisions. Philosophy in general and metaphysics in special are for him empty and dangerous forms of talk produced by enemies of the working class. As Neurath repeats ad nauseam, an essential task of the Vienna Circle is the full elimination of metaphysics and philosophy, which entails a thorough cleansing of all philosophic-speculative remains within scientific language. (To quote only a few examples: Neurath 1981/29B, 1981/31A, B, C and D, 1981/1932A, 1981/1933A) About the language of physics Neurath is optimistic for he believes its received metaphysical nonsense is cleared away for good. But he is rather critical about languages of sociology and psychology that wrap up a great deal of speculative pseudo-concepts. In sociology Neurath's main target is Max Weber whose social thought is taken by him as a privileged example of an unacceptable view of society. (Neurath, 1981/1931B: 415 and D: 462-5) Speaking about his contemporary psychology, Neurath considers Watson's behaviourism, the gestalt, Freudian psychoanalysis and individual therapy. He has minor criticisms against psychoanalysis, but he is rather stern about the other tendencies. Watson's discussions on ethics are plainly dropped as metaphysics. (Neurath 1981/1933: 601-8)

In 1931 Neurath popularises his views on physicalism in two short but enlightening articles. One of them was published in English in the USA (Neurath, 1981/1931B), while the other was written in German and published in Italy. (Neurath, 1981/1931C) In both of these works, besides his usual criticisms against metaphysics and philosophy, he explains very clearly his theses on language and unified science. For him, language is present from the very beginning in any sort of intelligent activity. Therefore, it would be meaningless to try to validate language through pre-linguistic resources like comparing it with the world, in order to make sure that it is really adequate. Even a simple language is about bodies, their properties and rela- 
tions, which expands to every meaningful kind of human linguistic expression. Science develops within language and cannot be severed from it. But the alpha and the omega of science are its forecasts. The business of science has nothing to do with any sort of description of the world nor with speculation, for science is public knowledge, whose sentences are due to be submitted to public tests. Eventually science produces forecasts useful to society in its activities of deciding and planning.

In these 1931 articles Neurath emphasizes the importance of behavioural psychology, despite his rejection of its specific theses. Almost two decades before, in 1913, John Watson had published in the USA his well-known manifesto termed Psychology as the Behaviorist Views It. (Watson, 1913) Watson's programme was to build a psychology concerned with observable behaviour, in order to put it on the path of sciences like physics, chemistry and biology. But Neurath surprisingly inverts this order, saying that sciences are concerned with the behaviour of nature: mineralogy for instance studies the behaviour of stones. (Neurath, 1981/31B: 413-4). In this sense every science is behavioural, because it deals with the observable conduct of objects that are in space and time. Watson was engaged in a form of psychology that, generally speaking, gets rid of concepts like mind, consciousness and the like. Introspection in particular is strongly rejected by Watsonian psychology. This is precisely the frame that Neurath includes in his version of physicalism, especially in relation to sociology. In a book published also in 1931, he describes sociology as 'social physics' (an expression originally by Quételet) or 'social behaviourism'. (Neurath 1981/31D: 500-26) Sociology has nothing to do with empty ideas like Volksgeist for instance, which are popular among social scientists, despite their character of metaphysical remains waiting to be cleared away. The true business of sociology is the study of human beings, who are stimulated by other human beings and by their environment. They work, they play, they are consumers, or, briefly, they behave.

Neurath extends this behavioural view to the statements of an individual person. If someone says, for example, 'I see something blue' this statement will be taken as an empirical sentence (Realsatz) if outside of the person's body some space-temporal things of the correspondent kind happen. The statement will be considered to be 
a hallucination if everything that happens is some change in the person's brain. Finally the statement will be taken as a lie if only the person's language-centre and its expression are changed. Thank to this type of scheme, Neurath is able of comprehend human expressions in purely behavioural terms. (Neurath 1981/1931C: 420)

In his two popular articles of 1931 Neurath presents the process of constitution of the unified science (Einheitswissenschaft), which is the sequence of space-temporal sentences together with their ramifications. The unified science includes logics and its tautologies, which are only rules for the transformation of sentences. Proper science starts with observational statements (Beobachtungssätze). Induction has no theoretical justification, but it is actually used based upon some methodological decision. Scientific laws obtain inductively from singular sentences. Such laws are not proper universal sentences, but they are only rules for the inference of statements related to singular forecasts, which have to be submitted to empirical tests. Neurath emphatically sustains the thesis that sentences cannot be compared with the world, but only with other sentences. Without any detail, he says that sentences are submitted to empirical tests within contexts where light, sounds and the like are present. Despite this, light and sounds are not elements of the unified science, whose only constituents are sentences. The test of a sentence produces other sentences. If a single sentence can be consistently added to the unified science, it is considered to be "true." If not, it is taken as "false." It is not comfortable for Neurath to use philosophical language, which is the reason why he writes words like these with inverted commas. For him, there is no other way of speaking about "truth." (Neurath 1981/1931C: 418-9) He refused the accusation of being a coherentist.

In 1931 Carnap publishes an article on the physicalist language as the universal language of science, where he partially preserves some phenomenalist elements of the Aufbau. The test of sentences of an empirical system, Carnap says, leads eventually to protocol or observation statements (Protokollsätze), which deal directly with basic experiences. Such elementary statements need no further tests. (Carnap 1931: 437-41)

In German "Protokoll” means something like a register or record. In this sense, protocol-statements are reliable registers of what a sci- 
entist verifies within a single experiment, under particular spacetemporal conditions. For instance, if he describes what happened in his experiment the scientist writes down records of a day, of an hour, of a place and other conditions. Eventually he may write something like "A noise was heard followed by a smell of ozone". This sentence is phenomenic, because it describes what was individually perceived by the scientist. Accordingly to Carnap, the test is complete when protocol-statements obtain.

A strong behaviourist and physicalist like Neurath could not accept Carnap's thesis, which caused him to publish one of his most elaborate and artful works: his essay on protocol-statements, originally published in the journal Erkenntnis, in1932. (Neurath 1981/1932B) In this article Neurath reaffirms his idea of a physicalist language as something that human beings have from their early life, as trivial historic language is taught to everyone since childhood. On the other extremity, sophisticated scientific language include highly complex space-temporal co-ordinates. Neurath persists in his programme towards the actual constitution of this kind of physicalist language, which for him would be the only possible task for the Vienna Circle. The programme should firstly involve a complete cleansing of all metaphysical remains within natural language. After this Neurath's language for the unified science would be woven like a seamless piece of cloth. As Neurath remarks, trivial colloquial language allows nonsensical expressions like 'a neighbour without a neighbour' for instance, which may be the root of speculative pseudo-problems. But the language for unified science is not supposed to be absolutely clean and transparent, because it is impossible to eliminate all sorts of ambiguities in it. Such a language cannot get rid of the so-called "agglomerations" (Ballungen), which are imprecise terms that cannot be replaced by sharply defined ones. (Neurath 1981/1935) If an "agglomeration" is eliminated somewhere, it will reappear in another point. As a matter of fact, Neurath vividly opposed any idea of a flawless language. But imprecision is not a logical mistake.

In addition to this, Neurath also opposed any sort of metalanguage for his unified language, because one part of the latter may speak about another of its parts. The unified language does not need a second language to deal with it.

The original point in Neurath's main article on protocol-state- 
ments is his formulation of what is a protocol. He drops his former speech about observational sentences in favour of Carnapian protocols, but his meaning is totally different. Neurath illustrates his idea with a famous example:

“Otto's protocol at 9:17 a.m.: [At 9:16 a.m. Otto's linguistic thought was like this: (At 9:15 a.m. there was in the room one table perceived by Otto.)]" (Neurath 1981/1932B: 580)

By elimination of square and round parentheses in this example, empirical sentences obtain, which are not protocols. A protocol must contain a person's name and a term relative to perception.

At first sight this characterisation looks rather weird, but it tries to capture the idea of a register written by someone who identifies himself and his perception. Nevertheless Neurath does not intend to admit irreducible psychological concepts. On the contrary: he insists that everything in a protocol-statement may be translatable into a space-temporal language, i.e. into a behavioural language. The important item is that the name and the perception-term indicate reference-points for the test of a protocol. If changes outside Otto's body happen, his statement will be empirical; if changes are limited to areas of his brain, the statement will be a hallucination; if only his language-centre is involved, the statement will be a lie. Anyway a protocol-statement has to be submitted to tests. Independently of this, and contrarily to Carnap's thesis, a protocol may be dropped, whenever it fails to be consistently included in the unified science.

Under Neurath's view there is one physicalist language and one unified science where protocol-statements are included. In science no sentence is privileged or untouchable. Any sentence is dischargeable and so is the set of sentences where they are supposed to be included. If there is a contradiction between a protocol-statement of mine and a protocol by someone else, I may prefer the latter to the former. What is not admissible is a contradiction within the set of scientific sentences. If this happens, it is theoretically possible to keep one protocol-statement and to drop the set, which we hardly ever do. In science nothing is immune to revision.

Each individual person may test protocol-statements formulated by others, and he may do the same with his own protocols, whereby the procedures are the same. Unified science is social and it is 
changing all the time. Robinson Crusoe and Friday share the same language, a reason why they can mutually test their protocol-statements. In this context, Neurath repeats his famous metaphor, that we are like sailors, forced to rebuild our ships in high sea. Science is unstable but crucial for us, because of its ability to forecast. If an alien protocol-statement is useful to a better prediction, we may prefer it to our own formulations.

The idea of behaviourism Neurath borrows from Watson clearly plays an essential role as far as it makes possible, at least in principle, the reduction of all human conduct to space-temporal elements, which eliminates the Carnapian phenomenalism and even the distinction between two kinds of psychical contexts present in the Aufbau. Thanks to the overall behavioural frame, physicalism can avoid talking about mind, consciousness, introspection and the like. This eliminates traditional psychology and allows Neurath's programme to be complete. Scientific sentences and protocols are not submitted to tests by means of procedures that lead to what one meets only in his own self. On the contrary: within the context of the same language, a test involves resources to the same physical and behavioural course of action. Behaviourism is the touch-stone of Neurathian physicalism.

Surprisingly enough Neurath speaks rather little about Watson's behaviourism, whose most general attitude he accepts, but whose specific theories he considered vague or even nonsensical. In order to distance himself from that early behaviourism, Neurath proposed new German words: Behaviorist is a representative of Watson's behaviourism; Behavioristiker is someone committed with the programme of a physicalistic language for the unified science. This programme extends very naturally into a social behaviourism (Sozialbehavioristik), that Neurath brings near to Marxism. (Neurath 1981/1933: 600-4)

It is true that Neurath speaks about behaviourism and about physicalism as programmes or tasks to be developed, because they actually do not exist yet. His characterisation of the language of unified science is a remarkable effort that ought not to conceal a considerable degree of imprecision and even of arbitrariness. For instance Neurath's thesis about the relation (or lack of relation) between sentences and the world is not explained in any detail by him. His concern to rule out metaphysics takes up an important part of his writings, in 
disfavour of some interesting contributions he gives. It is true that Neurath plainly did not want to make any sort of philosophy, but this does not justify any theoretical arbitrariness. He was always prepared to apply a sharp Neurathian razor to every statement he considered to be metaphysical, without establishing criteria for this sort of judgement.

In contemporary terms, Neurath can be classified as a naturalist and anti-realist. Neurath is a naturalist because he doesn't admit the existence of any level of knowledge superior to science, able to evaluate science itself. Anti-realist because his view of science is that of the boat to be kept afloat, insofar as it forecasts future events, which has nothing to do with any description of reality. In other words, the set of scientific sentences is a socio-linguistic fact, whose nature is pragmatic.

Neurath's pragmatism is very present in his objections against metalanguage and semantics. For him both are metaphysics. His theses on the subject and his controversies with other physicalists are by themselves a chapter in the history of the later Vienna Circle. Independently of this and within a different context, Michael Dummett writes in 2010, that a semantic theory has a link with metaphysics. (Dummett 2010: 130) If Dummett is right, Neurath's criticisms against semantics are not based on misunderstanding, at least from the point of view of his particular brand of physicalism.

Neurath has been classified as a post-modernist as well, for he represents the view that the promise of Enlightenment has to be reconceptualised. (Cartwright et al. 1996: 254) Naturalist, anti-realist, post-modernist: all these descriptions prove that Neurath's thought is a challenge, just because it is so comprehensive and radical.

Nelson Gomes University of Brasília

\section{References}

Carnap, Rudolf. 1931. Die physikalische Sprache als Universalsprache der Wissenschaft. Erkenntnis, 2: 432-65.

Cartwright, Nancy et al. 1996. Otto Neurath - Philosophy Between Science and Politics. New York: Cambridge University Press.

Dummett, Michael. 2010. The Nature and Future of Philosophy. New York: Colum- 
bia University Press.

Neurath, Otto. 1981/1929A. Wissenschaftliche Weltauffassung - Der Wiener Kreis. Neurath, Otto. 1981, pp. 299-336.

Neurath, Otto. 1981/1929B. Wissenschaftliche Weltauffassung. Neurath, Otto. 1981, pp. $345-8$

Neurath, Otto. 1981/1931A. Weltanschauung und Marxismus. Neurath, Otto. 1981, pp. 407-12

Neurath, Otto. 1981/1931B. Physikalismus - Die Philosophie des Wiener Kreises. Neurath, Otto. 1981, pp. 413-6.

Neurath, Otto. 1981/1931C. Physikalismus. Neurath, Otto. 1981, pp. 417-22.

Neurath, Otto. 1981/1931D. Empirische Soziologie. Neurath, Otto. 1981, pp. 423-528.

Neurath, Otto. 1981/1932A. Die „Philosophie” im Kampf gegen den Fortschritt der Wissenschaft. Neurath, Otto. 1981, pp. 571-76.

Neurath, Otto. 1981/1932B. Protokollsätze. Neurath, Otto. 1981, pp. 577-86.

Neurath, Otto. 1981/1933. Einheitswissenschaft und Psychologie. Neurath, Otto. 1981 , pp. $587-610$

Neurath, Otto. 1981/1935. Einheit der Wissenschaft als Aufgabe. Neurath, Otto. 1981 , pp. 625-630

Neurath, Otto. 1981. Gesammelte philosophische und methodologische Schriften. 2 vols. ed. by Rudolf Haller und Reiner Rutte. Vienna: Hölder-Pichler-Tempsky.

Watson, John. 1913. Psychology as the Behaviorist Views It. Psychological Review, 20: $158-77$. 